Specification 156, Appendix A, and although it was possible to obtain all the required electrical properties at atmospheric temperatures, this was not so with some classes of enamel when the same tests were attempted in rising temperatures. As changes in power factor were being followed, a relatively high voltage between wires was used (about $1 \cdot 2 \mathrm{kV}$.), and it was found impossible to avoid premature breakdown of some classes of enamel when the temperature was raised rapidly. Evidently a means of controlling the voltage applied between wires was wanted so that as the temperature rose, the voltage would fall off; but it was not practicable to do this accurately and quickly enough with ordinary hand control.

Automatic voltage control was satisfactorily achieved by replacing the test transformer then in use by another having an extremely poor regulation. By this means the enamels which had hitherto broken down prematurely caused an increasing drain on the trensformer as the temperature rose, this being followed concurrently by a drop in voltage.
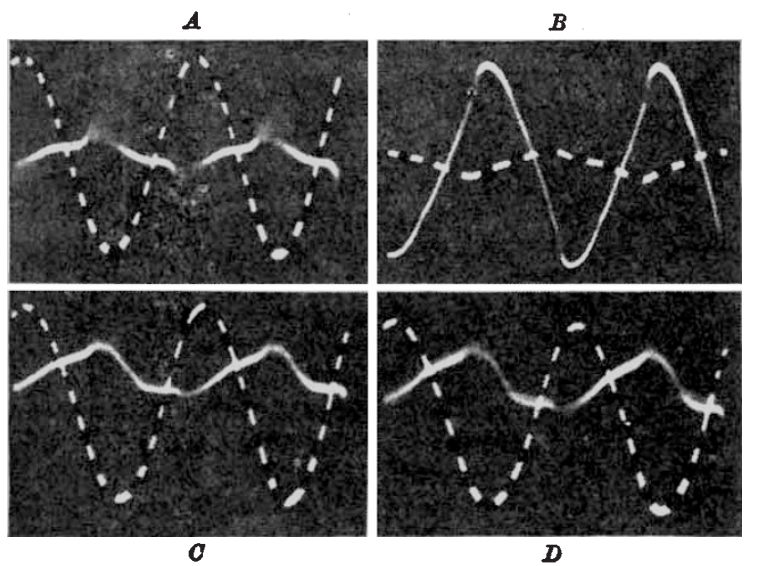

By connecting voltage and current leads to a double-beam cathode ray oscillograph with the usual $180^{\circ}$ phase shift, it was thus possible to follow changes in power factor with changes of temperature as rapid as $100^{\circ} \mathrm{C}$. per second, the required voltage regulation being entirely automatic. Oscillograms $A$ and $B$ represent conditions at $20^{\circ} \mathrm{C}$. and $120^{\circ} \mathrm{C}$. respectively, using an enamel sensitive to temperature; $C$ and $D$ are those for an enamel which shows little sensitivity to temperature. For clarity all voltage curves are shown dotted, and the interchange of eurrent and voltage magnitudes in the former case is thus shown very clearly. The 'haze' at the peaks of the current wave in oscillogram $A$ depicts a highfrequency discharge consequent upon the high voltage used, and this is naturally absent in oscillogram $B$, which illustrates a much lower voltage. This high-frequency discharge appears to be a characteristic of those enamels which are sensitive to temperature.

The change from condition $A$ to condition $B$ is not a chemical one, and on the oscillograph the gradual change from one extreme to the other could be observed any number of times as the temperature was raised and lowered.

$$
\text { H. A. Macdonald. }
$$$$
\text { E. C. R. Scarfe. }
$$

Research Laboratories,

W. T. Henley's Telegraph Works Co., Ltd., Gravesend,

Kent.

\section{Biological Control of the Fly Population in Sewage Filters}

IN his communication on "Town Planning and the Small Sewage Purification Plant", Dr. Lloyd ${ }^{1}$ discusses the problem of controlling the numbers of the sewage fly, Anisopus fenestralis, in and around sewage filters close to housing estates. Though Psychoda flies were also present in large numbers in these filters, they apparently caused little nuisance compared with that from the Anisopus flies, which entered the neighbouring dwellings in large numbers.

For the past two years observations have been made, as part of the programme of the Water Pollution Research Board of the Department of Scientific and Industrial Research, of the seasonal variation in the fly population in large-scale percolating filters at the Minworth works of the Birmingham Tame and Rea District Drainage Board. The results suggest a possible answer to the question raised by Dr. Lloyd.

The four filters under observation at Minworth have a varied fauna composed mainly of Psychoda alternata, Anisopus fenestralis, Achorutes viaticus, and Enchytræid worms. It was , found that under optimum conditions of growth, Anisopus fenestralis took $121,73,50$ and 39 days at $9^{\circ} \mathrm{C} ., 13^{\circ} \mathrm{C} ., 18 \cdot 5^{\circ} \mathrm{C}$. and $21^{\circ} \mathrm{C}$. respectively to complete its life-cycle. With a restricted food supply, however, the duration of the life-cycle may be much longer than is indicated by these figures. Whereas Psychoda alternata is restricted to the warmer months ${ }^{2}$, the temperature of the filters is normally favourable throughout the year for the development of Anisopus. The filters therefore carry during the winter months a large potential population of flies which emerge in the spring if weather conditions and conditions in the filters are favourable. If the surface layers of the filters are open, Anisopus emerges in large numbers during periods of warm weather in the spring. The numbers decline in the late spring and early summer, when Psychoda alternata begins to breed in large numbers in the filters.

At summer temperatures it appears that Psychoda alternata is more effective than Anisopus as a scouring organism. Under certain conditions the accumulation of solid matter in the upper layers of a filter may be sufficient in amount to prevent the emergence of Anisopus without impairing the efficiency of the filter by causing serious ponding on the surface. Such conditions may prevail in the spring in filters operated at high rates as alternating double filters with a short period of alternation, or in a filter treating a mixture of sewage and effluent at a high rate. The emergence of large numbers of Anisopus in the spring is thus prevented. The filters at Minworth became cleared of solid matter by summer owing to the scouring activity of Psychoda. Numerous Psychoda but few Anisopus emerged from these filters during the summer.

The successful competition of Psychoda with Anisopus in these filters is a good example of natural biological control, and the observations recorded suggest another line of approach to the problem raised by Dr. Lloyd, which is consistent with the operation of filters at their maximum capacity.

T. G. TOMLINSON.

Water Pollution Research Laboratory, Minworth, Birmingham.

${ }^{1}$ Lloyd, Ll., NATURE, 161, 475 (1943). - Lloyd, Ll., Graham, J. F., and Reynoldson, T. B., Ann.Appl. Biol. 